\title{
Time period and nutrient contents alter the mycorrhizal responsiveness of citrus seedlings
}

\author{
İ. Ortas ${ }^{1}$,A. Demirbas ${ }^{2}$ and C. Akpinar ${ }^{3}$ \\ ${ }^{1}$ University of Çukurova, Department of Soil Science and Plant Nutrition, Adana, Turkey \\ ${ }^{2}$ University of Cumhuriyet, Sivas Vocational School, Department of Crop and Animal Production, Sivas, Turkey \\ ${ }^{3}$ University of Osmaniye Korkut Ata, Kadirli School of Applied Sciences, Department of Organic Farming Business \\ Management, Osmaniye, Turkey
}

\section{Summary}

It is necessary to know the nutrient requirement of citrus plants during the growing period to ensure optimal growth. As fertilizers are limited and expensive, in addition to the unknown long-term environmental aspect, it is good practice to use plant rhizosphere mechanisms, such as mycorrhizal inoculation, to enhance growth. As citrus plants depend on mycorrhizae colonization, it is beneficial to inoculate seedlings with mycorrhizae at an early stage. Thus, investigating citrus seedling quality and nutrition, with and without mycorrhizae, under greenhouse conditions is important in order to elucidate the impact of mycorrhizae in the eastern Mediterranean region. The aim of this study was to determine the role of mycorrhizal inoculation on citrus seedling growth, nutrient uptake and mycorrhizal dependency at specific time intervals. The experiments were set up under greenhouse conditions, using mycorrhiza-inoculated and non-inoculated sour orange seedlings grown over 15 months, which were harvested seven times.

Citrus seedlings were extensively colonized by mycorrhizae and root colonization started 5-6 months after germination. Mycorrhizae inoculation increased certain growth parameters including shoot diameter, shoot height, and shoot and root dry weight. As the plant developed over time, the nutrient concentration, especially $\mathrm{P}, \mathrm{Zn}, \mathrm{Fe}, \mathrm{Mn}$, and $\mathrm{Cu}$ in the leaves decreased in both inoculated and non-inoculated seedlings. Over this time period, the seedlings initially absorbed nutrients more rapidly than later on due to dilution effects. Mycorrhizal Responsiveness (MR) between harvest times was calculated and showed that MR increased with plant growth over time.

Keywords

citrus growth, plant nutrition, dilution effect,

mycorrhizal colonization, mycorrhizal responsiveness

\section{Introduction}

Most citrus fruit is grown under Mediterranean climate conditions. Soils under semi-arid and sub-tropical conditions have high clay, $\mathrm{CaCO}_{3}$ and $\mathrm{pH}$, and less organic carbon. Since citrus cultivation is expected to expand in the Mediterranean region, the demand for virus-free citrus seedlings has increased. In addition, as virus-free citrus seedling production during in vitro culture uses a high amount of fertilizer, it is

\section{Significance of this study}

What is already known on this subject?

- In this work we examine the effect of harvesting time on nutrient concentration and plant growth parameters. The aim of the study was to determine the effects of selected arbuscular mycorrhizae (AM) inoculation on the growth and nutrient uptake of sour orange (Citrus aurantium L.) seedlings with time.

What are the new findings?

- We found that with time nutrient concentration of citrus seedling decreased. Also mycorrhizal responsiveness increased with time.

What is the expected impact on horticulture?

- Mycorrhiza has a great importance for sustainable agriculture, which enhances the growth of citrus plants/sour orange especially in the soils with $\mathrm{P}$ and Zn deficiency. The results are strongly suggesting that under field conditions mycorrhizal inoculation is necessary for better plant growth even under nonsterile conditions.

difficult to transplant from greenhouse to field conditions without providing sufficient fertilizer and appropriate growing conditions. Since the soils in the region exhibit fertility problems, farmers are demanding virus-free seedlings that can adapt to poor soil conditions as plants in citrus-growing soils generally exhibit $\mathrm{P}, \mathrm{Zn}$ and Fe deficiency.

Wang and Xia (2009) showed that colonization with G. versiforme significantly increased plant height, stem diameter, leaf numbers and dry mass. G. mosseae-inoculated citrus-grafted trifoliate orange seedlings exhibited a significant increase in plant height, stem diameter, leaf area and shoot length (Wu et al., 2017; Wu and Xia, 2005). Sharma et al. (2009) reported a significant increase in growth parameters, namely height, diameter, root length, and leaf area, which were more evident for seedlings inoculated with G. fasciculate and G. mosseae. Similarly, the results of Cho et al. (2009) showed that plant growth characteristics, such as plant height, root length, leaf area, number of lateral roots, fresh weight of shoots and roots, and chlorophyll content, were significantly enhanced in Arbuscular Mycorrhizal Fungus (AMF) inoculated seedlings compared with non-inoculated seedlings.

AM mycorrhiza not only take up P but can also take up 
$\mathrm{Zn}, \mathrm{Cu}, \mathrm{Mn}, \mathrm{Fe}, \mathrm{Ca}, \mathrm{K}$ and $\mathrm{NH}_{4}$ (Ortas, 2012a). Srivastava et al. (2002) reported that mycorrhiza-treated citrus trees exhibited improved plant growth and uptake of nutrients such as P, Zn (Zubek et al., 2015), Cu and Fe compared with non-mycorrhizal trees. Youpensuk et al. (2008) indicated that AM fungi increased concentrations of $P$ in leaves of citrus tangerine. Kothari et al. (1991) and Li et al. (1991) calculated the contribution of mycorrhiza on $\mathrm{Zn}$ uptake and found that $60 \%$ of $\mathrm{Zn}$ is taken up by the rhizosphere. Ortas and Ustuner (2014) used different mycorrhiza species with a different growth medium and found that mycorrhiza-inoculated citrus seedlings exhibited high shoot and root development. It is therefore prudent to investigate mycorrhiza-inoculated and non-inoculated plant nutrient concentrations during plant growth to achieve better nutrient management.

Transplanting citrus seedlings to the field in certain soils causes high seedling mortality. Farmers use a large quantity of fertilizer without considering soil and water quality; in addition, sources of fertilizer are limited and expensive. Using a large quantity of fertilizer, especially phosphorus, has a negative effect on the plant's natural defenses and nutrient uptake mechanisms; hence, citrus plants are unable to achieve optimum development without mycorrhizae (Ortas et al., 2016). Mycorrhiza-inoculated plants have more root and root hair, and mycorrhiza can also contribute to nutrient uptake through roots and external hyphae. In this manner, mycorrhiza provides optimal chemical, biological and physical soil conditions for citrus plants which are sensitive to nutrient-deficient soil conditions. Citrus plant nutrient uptake is dependent upon seasonal changes; however, the role of mycorrhizae on seasonal nutrient uptake during seedling growth periods is unknown. It is very important to develop a fertilization programme to match the requirements of seedlings under mycorrhizal and non-mycorrhizal conditions.

The aim of this work was: (a) to determine the growth dynamics of citrus seedlings over several harvesting intervals; (b) to determine the concentrations of $\mathrm{P}, \mathrm{K}, \mathrm{Zn}, \mathrm{Cu}, \mathrm{Mn}$ and $\mathrm{Fe}$ in the citrus seedlings at harvest times; and (c) to compare harvesting time mycorrhizae dependency to determine an effective inoculation time.

\section{Materials and methods}

Experiments were performed using a growth medium (GM) which has been previously used by Ortas et al. (2002), i.e., andesitic tuff, soil and compost $(6: 3: 1 \mathrm{v} / \mathrm{v})$. The GM was sterilized by autoclaving at $120^{\circ} \mathrm{C}$ for 2 hours and after 3 weeks the GM was ready to balance microbial activities. Soil material was collected from surface horizons of the clay loam Menzilat soil series (0-20 cm) (Typic Xerofluvents) in the Çukurova Basin, which had a $\mathrm{pH}$ of 7.98 and the $0.5 \mathrm{M}$ $\mathrm{NaHCO}_{3}(\mathrm{pH}=8.5)$ extractable P was $87.6 \mathrm{~kg} \mathrm{ha}^{-1} \mathrm{P}$. Compost had the following characteristics: $\mathrm{pH}$ of $7.91,31.6 \%$ organic carbon, $1.13 \% \mathrm{~N}, 0.18 \% \mathrm{P}$ and $0.98 \% \mathrm{~K}$. Andesitic tuff contained $4.3 \% \mathrm{~K}$ and $0.03 \% \mathrm{P}$. The physical and chemical characteristics of the GM (soil, compost and andesitic tuff) were measured according to Page et al. (1982) in the Rhizosphere Laboratory of Çukurova University, Adana, Turkey.

\section{Production of seedlings}

Tuzcu-31-31 sour orange (Citrus aurantium L.) variety seeds were germinated in perlite growth medium. Perlite was washed twice with water, washed with $2 \% \mathrm{HCl}$ and then washed with distilled water. Seeds were sown and grown for 35 days in perlite trays; when the seedlings grew to a 3-4 leaf stage they were transplanted into $3-\mathrm{kg}$ black plastic bags.

\section{Experimental design}

Seedlings were grown in the perlite GM until they displayed three leaves. The experiment was completely randomized with 15 replicates. After the seedlings were transplanted from the perlite medium to pots, the mycorrhizae inoculated and non-inoculated plantlets were grown for 15 months in a controlled temperature glasshouse with daynight temperatures of $26 \pm 2^{\circ} \mathrm{C}$. Rhizophagus clarus (Schüßler and Walker, 2010) Nutri-Link isolate, USA was used as a mycorrhizal inoculum. Before transplanting seedlings to pots, 5000 spores were applied $50 \mathrm{~mm}$ under the seedling roots at transplanting stages. Non-inoculated seedlings were transplanted into pot without an inoculum and received a similar quantity of mycorrhiza-free media. Inoculum concentration was determined as the number of spores $10 \mathrm{~g}^{-1}$ inoculum (spore, hyphae and growth media) on a dry weight basis.

The experiment was set up as a completely randomized factorial experiment with 105 mycorrhizal and non-mycorrhizal seedlings. For each harvest 15 seedlings were randomly selected and harvested.

The GM was treated with $200 \mathrm{mg} \mathrm{N} \mathrm{kg}-1\left(\mathrm{NH}_{4} \mathrm{NO}_{3}\right)$. The plants were grown in a greenhouse at $24-25^{\circ} \mathrm{C}$ and at a relative humidity of $60-70 \%$, with a $16 \mathrm{~h}$ day and $8 \mathrm{~h}$ dark photoperiod. Distilled water was added daily to maintain the moisture at $80 \%$ of field capacity. During the 15 -month growing period, seedlings were regularly phonologically observed for nutrient deficiency and any other issues.

\section{Biomass assessment and nutrient analysis}

Seedlings were harvested seven times during the 15 month growing period $(30.03 .2005,27.06 .2005,02.09 .2005$, 10.11.2005, 04.01.2006, 10.03.2006, 24.06.2006). After each harvest, the shoot length $(\mathrm{cm})$, shoot diameter $(\mathrm{mm})$, shoot and root dry weight $\left(\mathrm{g} \mathrm{plant}^{-1}\right)$, root height $(\mathrm{cm})$, root colonization and nutrient uptake were measured. All the leaf samples were first washed quickly with tap water, passed through $0.1 \% \mathrm{HCl}$, tap water and then washed twice with distilled water. They were then dried for $48 \mathrm{~h}$ at $65^{\circ} \mathrm{C}$ until a constant weight was reached and the shoot and root dry weight were then determined. Dried material from each pot was ground using a Tema mill and $0.2 \mathrm{~g}$ of the ground plant material was then ashed at $550^{\circ} \mathrm{C}$ followed by dissolution in $3.3 \% \mathrm{HCl}$. After digestion of the plant material, the concentration of P in this solution was determined calorimetrically according to Murphy and Riley (1962) using a flame photometer. An atomic absorption spectrophotometer (Perkin Elmer) was employed to determine the concentration of $\mathrm{K}, \mathrm{Zn}, \mathrm{Fe}$, $\mathrm{Mn}$ and $\mathrm{Cu}$ in the plant samples.

\section{Mycorrhizal colonization (\%)}

After each harvest, the shoots were separated from the roots $0.5 \mathrm{~cm}$ above the soil surface; the roots were then separated from the soil by washing with running tap water and several times with distilled water. Prior to drying the roots at $65^{\circ} \mathrm{C}$ for $48 \mathrm{~h}$, small sub-samples (representing all roots) were taken and preserved in a mixture of ethanol, glacial acetic acid and formalin (250:13:5 V/V/V) to determine mycorrhizal colonization. Portions of preserved roots were stained using the method of Koske and Gemma (1989). Mycorrhizal fungus colonization was determined using the gridline-intersect method of Giovanetti and Mosse (1980).

\section{Mycorrhizal dependency (MD)}

At harvest, the effect of AMF on the mycorrhizal dependency of shoot dry weight was calculated based on the fol- 
lowing formula:

Mycorrhizal Responsiveness $(M R)=\frac{\text { Yield }(+\mathrm{M})-\text { Yield }(-\mathrm{M})}{\text { Yield }(+\mathrm{M})} \times 100$

\section{Statistical analysis}

The variations in plant growth parameters were assessed via the analysis of variance ANOVA procedure using the SPSS 20.0 computer program. The main last significant effects were determined using the Tukey Test at $\mathrm{P}<0.05$.

\section{Results and discussion}

Experiments were harvested every 2-3 months, resulting in a total of seven harvests. At each harvest, the root and shoot dry weight, stem diameter, root height and nutrient concentration of plant tissue were analyzed in order to determine the impact of mycorrhizal inoculation.

\section{Mycorrhizal colonization}

Root colonization was determined in non-inoculated seedlings and, even though the GM was sterilized; these seedlings exhibited up to $2.67 \%$ colonization at harvests 5 and 6 . For mycorrhiza-inoculated seedling root colonization, the first experiment started with $6.67 \%$ and at the $7^{\text {th }}$ harvest increased up to $90.67 \%$ (Table 1). In mycorrhiza-inoculated seedlings, root colonization from the first two harvests was less than $10 \%$, and at the $3^{\text {rd }}$ and $4^{\text {th }}$ harvests the root colonization was $28 \%$ and $64.67 \%$, respectively. It appears that citrus roots exhibit efficient root colonization 5-6 months after germination. Nunes et al. (2006) collected soil and plant root samples to determine mycorrhizal development and found that root colonization is diverse and ranged from $42 \%$ to $83 \%$.

In woody plants, such as citrus, root colonization takes time to achieve sufficient colonization to aid plant develop- ment, which is an important aspect for future work and crucial for citrus mycorrhiza management. Ortas et al. (2002) indicated the importance of early root colonization for improved seedling transplantation into field conditions. Tissue nutrient concentrations were determined after each harvest. The morphology of the root system is a major determinant of nutrient uptake.

Tap root length (TRL) was also determined and in non-inoculated seedlings the root height was not significantly different (Table 1). Plant roots in harvests 5 and 6, exhibited the longest TRL with $36.13 \mathrm{~cm}$ and $37.53 \mathrm{~cm}$, respectively. Mycorrhiza-inoculated seedlings at harvest 7 had the longest TRL, with $45.73 \mathrm{~cm}$. Various studies investigating plant P deficiency conditions have shown that TRL increases under P deficiency. Chen et al. (2014) showed that mycorrhizal infection may encourage tree plant root growth and branching. Similar to our findings, Wu et al. (2010) found that mycorrhizal plants exhibited significantly higher root total length, surface area and volume compared with non-mycorrhizal plants.

\section{Plant growth parameters}

Shoot diameters increased upon mycorrhiza inoculation and with growth period. During seedling growth, the shoot diameter was measured and data evaluated. The shoot diameter of citrus seedlings of non-mycorrhiza-inoculated seedlings at the $1^{\text {st }}$ harvest generally was lower than other harvests, at $1.98 \mathrm{~mm}$. However, in mycorrhiza-inoculated seedlings at the $1^{\text {st }}$ harvest the value was $2.39 \mathrm{~mm}$. At harvest 7 , the values for non-mycorrhizal plants were $3.50 \mathrm{~mm}$ and for mycorrhizal plants were $7.10 \mathrm{~mm}$, respectively. Mycorrhiza-inoculated seedlings exhibit nearly double the shoot diameter of non-inoculated seedlings (Table 1). Shoot length also increased upon mycorrhizal inoculation and, with time,

TABLE 1. Effect of mycorrhizal inoculation on citrus growth parameters during several harvesting times.

\begin{tabular}{|c|c|c|c|c|c|c|c|c|}
\hline Harvesting time & \multicolumn{2}{|c|}{$\begin{array}{l}\text { Shoot diameter } \\
(\mathrm{mm})\end{array}$} & \multicolumn{2}{|c|}{$\begin{array}{l}\text { Shoot length } \\
(\mathrm{cm})\end{array}$} & \multicolumn{2}{|c|}{$\begin{array}{l}\text { Tap root length } \\
\text { (cm) }\end{array}$} & \multicolumn{2}{|c|}{$\begin{array}{l}\text { Root colonization } \\
(\%)\end{array}$} \\
\hline \multicolumn{9}{|c|}{ Non-mycorrhizae } \\
\hline 1. Harvest & 1.98 & $\pm 0.2 \mathrm{~h}$ & 14.27 & $\pm 2.32 \mathrm{e}$ & 33.57 & $\pm 6.8 \quad a b$ & 0.67 & $\pm 2.58 \mathrm{~d}$ \\
\hline 2. Harvest & 2.81 & $\pm 0.54 \mathrm{f}-\mathrm{h}$ & 17.50 & $\pm 5.6 \mathrm{e}$ & 33.27 & $\pm 10.9 \mathrm{ab}$ & 0.00 & $\pm 0.00 \mathrm{~d}$ \\
\hline 3. Harvest & 3.43 & $\pm 1.11 \mathrm{e}-\mathrm{g}$ & 35.07 & \pm 22.31 c-e & 34.07 & $\pm 6.18 \mathrm{ab}$ & 1.33 & $\pm 3.52 \mathrm{~d}$ \\
\hline 4. Harvest & 3.33 & $\pm 1.44 \mathrm{e}-\mathrm{g}$ & 25.07 & \pm 24.36 c-e & 31.47 & $\pm 11.15 \mathrm{~b}$ & 2.00 & $\pm 4.14 \mathrm{~d}$ \\
\hline 5. Harvest & 1.85 & $\pm 0.81 \mathrm{~h}$ & 32.53 & \pm 23.26 c-e & 36.13 & $\pm 5.79 a b$ & 2.67 & $\pm 5.94 \mathrm{~d}$ \\
\hline 6. Harvest & 3.91 & \pm 1.28 ef & 39.60 & $\pm 24.64 \mathrm{~cd}$ & 37.53 & $\pm 8.77 \mathrm{ab}$ & 2.67 & $\pm 5.94 \mathrm{~d}$ \\
\hline 7. Harvest & 3.50 & $\pm 1.22 \mathrm{e}-\mathrm{g}$ & 18.76 & $\pm 61.01 \mathrm{de}$ & 32.56 & $\pm 16.95 \mathrm{~b}$ & 2.00 & $\pm 0.00 \mathrm{~d}$ \\
\hline \multicolumn{9}{|c|}{ Mycorrhizal inoculation } \\
\hline 1. Harvest & 2.39 & $\pm 0.26 \mathrm{gh}$ & 18.10 & $\pm 2.21 \mathrm{de}$ & 34.83 & $\pm 8.64 a b$ & 6.67 & $\pm 7.24 \mathrm{~d}$ \\
\hline 2. Harvest & 4.19 & $\pm 0.71 \mathrm{de}$ & 45.50 & $\pm 9.43 \mathrm{c}$ & 39.27 & $\pm 11.09 \mathrm{ab}$ & 9.33 & $\pm 10.33 d$ \\
\hline 3. Harvest & 5.38 & $\pm 1.2 \mathrm{~cd}$ & 73.17 & $\pm 23.04 \mathrm{~b}$ & 32.73 & $\pm 8.02 \mathrm{~b}$ & 28.00 & $\pm 16.56 \mathrm{c}$ \\
\hline 4. Harvest & 5.57 & $\pm 1.41 \mathrm{bc}$ & 76.33 & $\pm 22.85 \mathrm{~b}$ & 39.20 & $\pm 11.44 \mathrm{ab}$ & 64.67 & $\pm 15.06 \mathrm{~b}$ \\
\hline 5. Harvest & 5.85 & $\pm 1.03 \mathrm{a}-\mathrm{c}$ & 79.47 & $\pm 18.78 \mathrm{~b}$ & 42.87 & $\pm 8.03 \mathrm{ab}$ & 76.67 & $\pm 21.6 \quad b$ \\
\hline 6. Harvest & 6.71 & $\pm 1.33 \mathrm{ab}$ & 86.50 & $\pm 15.4 \mathrm{ab}$ & 43.16 & $\pm 11.06 \mathrm{ab}$ & 88.40 & \pm 1.06 a \\
\hline 7. Harvest & 7.10 & $\pm 0.74 \mathrm{a}$ & 102.87 & $\pm 16.26 \mathrm{a}$ & 45.73 & $\pm 10.73 \mathrm{a}$ & 90.67 & \pm 7.99 a \\
\hline
\end{tabular}

\begin{tabular}{llcccc}
\hline Treatment & Df & Shoot diameter & Shoot length & Tap root length & Root colonization \\
\hline Mycorrhiza (M) & 1 & $<.001$ & $<.001$ & $<.001$ & $<.001$ \\
Harvest time $(\mathrm{H})$ & 6 & $<.001$ & 0.020 & $<.001$ & $<.001$ \\
$\mathrm{M} \times \mathrm{H}$ & 6 & $<.001$ & $<.001$ & 0.264 & $<.001$ \\
\hline
\end{tabular}

\pm Standard error (mean of 15 seedlings). 
the shoot length of mycorrhiza-inoculated seedlings was several folds higher than non-inoculated seedlings. In non-inoculated seedling, in $7^{\text {th }}$ harvest time shoot length relatively is reduced to $6^{\text {th }}$ harvest. Since soil was sterilized and citrus seedlings are mycorrhiza-dependent, seedlings are stunted. In $7^{\text {th }}$ harvest time shoot length is $18.76 \mathrm{~cm}$ and standard error is 61.01. It seems that variation in between treatments is high in this harvest time. Statistically, the growth parameters were significant.

Mycorrhizal inoculation significantly increased the seedling shoot dry weight (SDW). At the $1^{\text {st }}$ harvest, non-inoculated seedlings contained $0.61 \mathrm{~g} \mathrm{pot}^{-1} \mathrm{SDW}$ and after 15 months, at harvest 7 (Table 2), the SDW was 4.65 g pot $^{-1}$. Mycorrhiza-inoculated seedlings at the $1^{\text {st }}$ harvest had $1.00 \mathrm{~g} \mathrm{pot}^{-1}$ and mycorrhiza-inoculated seedlings at harvest 7 produced $20.29 \mathrm{~g} \mathrm{pot}^{-1}$. Root dry weight had a similar growth response to shoot dry weight. In summary, depending on the development time of the plants inoculated with mycorrhizae, it was determined that mycorrhizal inoculation increased dry matter production and assisted healthy growth.

In mycorrhiza-inoculated seedlings, the highest dry matter production was observed at harvests 6 and 7 . Sour orange is mycorrhiza-dependent under sterile and non-inoculation conditions, hence the plants did not grow properly as the GM was sterilized and no beneficial organisms were present to exert an effect on seedling growth. Previously, Levy et al. (1983) showed that under sterile and less fertile soil conditions, mycorrhiza-inoculated seedlings grow better. Youpensuk et al. (2008) reported that under greenhouse and field conditions with low $\mathrm{P}$ soil concentrations, AM fungal inoculation increased mandarin (Citrus reticulata) growth and development.

The development of woody plants, especially during the beginning of a pause stage, is hindered if the plant does not obtain sufficient nutrients. Hence, it is very important to know the physiological status of citrus plants when inoculating seedlings with mycorrhizae in order to overcome any issues that could potentially stunt growth. Root dry weight (RDW) was determined and it was found that at harvest 7, non-inoculated seedlings had the highest RDW (Table 2), with $3.10 \mathrm{~g} \mathrm{pot}^{-1}$, and in mycorrhiza-inoculated seedlings it was $12.62 \mathrm{~g} \mathrm{pot}^{-1}$. RDW of harvest 6 seemed to be less than the result for harvest 5 . Since for each harvest the mean of 15 seedlings were used and also seedlings were randomly selected, possibly there is large variation and standard error. The root and shoot ratio decreased with time of harvest and is an important parameter in terms of plant development. Root/shoot ratios indicated that plant mycorrhizae dependency decreases as the capacity for root production increases.

The results are supported by the observations of Ortas and Ustuner (2014), who also observed that $R$. clarus is an efficient inoculum for root growth. Wu and Zou (2009) showed that sole AMF inoculation significantly increased total dry weight, and leaf and root nutrient content of the citrus seedlings, compared with the non-AMF control. In general, for both inoculated and non-inoculated seedlings, plants grew bigger with time and the plant tissue nutrient concentration decreased, which may be explained by diluting effects. As indicated responsiveness of mycorrhizae to plant growth is beyond the soil fertility and plant nutrition (Wu et al., 2017). Possibly mycorrhizae have some other benefits for plant growth and nutrient uptake in terms of increasing the resistance of plant against stress factors (Ortas, 2012b).

\section{Nutrient concentration}

Over the 15 months, the mycorrhiza-inoculated seedlings exhibited a higher $\mathrm{P}$ concentration than non-inoculated

TABLE 2. Effect of mycorrhizal inoculation on citrus growth parameters during several harvesting times.

\begin{tabular}{|c|c|c|c|c|c|}
\hline \multirow{2}{*}{ Harvesting time } & \multirow{2}{*}{\multicolumn{2}{|c|}{ Shoot dry weight }} & \multicolumn{2}{|c|}{ Root dry weight } & \multirow{2}{*}{ Root/Shoot } \\
\hline & & & \multicolumn{2}{|c|}{$\mathrm{g} \mathrm{pot}^{-1}$} & \\
\hline \multicolumn{6}{|c|}{ Non-mycorrhizae } \\
\hline 1. Harvest & 0.61 & $\pm 0.23 \mathrm{~d}$ & 0.61 & $\pm 0.19 \mathrm{e}$ & 1.00 \\
\hline 2. Harvest & 0.81 & $\pm 0.38 \mathrm{~d}$ & 0.66 & $\pm 0.38 \mathrm{e}$ & 0.81 \\
\hline 3. Harvest & 2.82 & $\pm 2.69 \mathrm{~d}$ & 1.71 & $\pm 1.82 \mathrm{de}$ & 0.61 \\
\hline 4. Harvest & 2.41 & $\pm 3.78 \mathrm{~d}$ & 1.36 & $\pm 1.72 \mathrm{e}$ & 0.56 \\
\hline 5. Harvest & 2.35 & $\pm 3.06 \mathrm{~d}$ & 2.59 & $\pm 2.28 \mathrm{de}$ & 1.10 \\
\hline 6. Harvest & 2.74 & $\pm 2.93 \mathrm{~d}$ & 1.26 & $\pm 1.01 \mathrm{e}$ & 0.46 \\
\hline 7. Harvest & 4.65 & $\pm 4.83 \mathrm{~cd}$ & 3.10 & $\pm 2.9 \mathrm{de}$ & 0.67 \\
\hline \multicolumn{6}{|c|}{ Mycorrhizal inoculation } \\
\hline 1. Harvest & 1.00 & $\pm 0.29 \mathrm{~d}$ & 0.79 & $\pm 0.29 \mathrm{e}$ & 0.78 \\
\hline 2. Harvest & 4.11 & $\pm 1.7 \mathrm{~cd}$ & 1.97 & $\pm 1.13 \mathrm{de}$ & 0.48 \\
\hline 3. Harvest & 8.38 & $\pm 4.28 \mathrm{bc}$ & 4.83 & $\pm 3.77 \mathrm{~cd}$ & 0.58 \\
\hline 4. Harvest & 11.67 & $\pm 5.26 \mathrm{~b}$ & 6.56 & $\pm 4.07 \mathrm{bc}$ & 0.56 \\
\hline 5. Harvest & 10.88 & $\pm 4.76 \mathrm{~b}$ & 9.08 & $\pm 4.61 \mathrm{~b}$ & 0.83 \\
\hline 6. Harvest & 17.64 & $\pm 4.27 \mathrm{a}$ & 7.93 & $\pm 1.63 \mathrm{bc}$ & 0.45 \\
\hline 7. Harvest & 20.29 & $\pm 4.98 \mathrm{a}$ & 12.62 & $\pm 3.76 \mathrm{a}$ & 0.62 \\
\hline
\end{tabular}

\begin{tabular}{llcc}
\hline Treatment & Df & Shoot DW & Root DW \\
\hline Mycorrhiza (M) & 1 & $<.001$ & $<.001$ \\
Harvest time (H) & 6 & $<.001$ & $<.001$ \\
$\mathrm{M} \times \mathrm{H}$ & 6 & $<.001$ & $<.001$ \\
\hline
\end{tabular}

\pm Standard error (mean of 15 seedlings). 


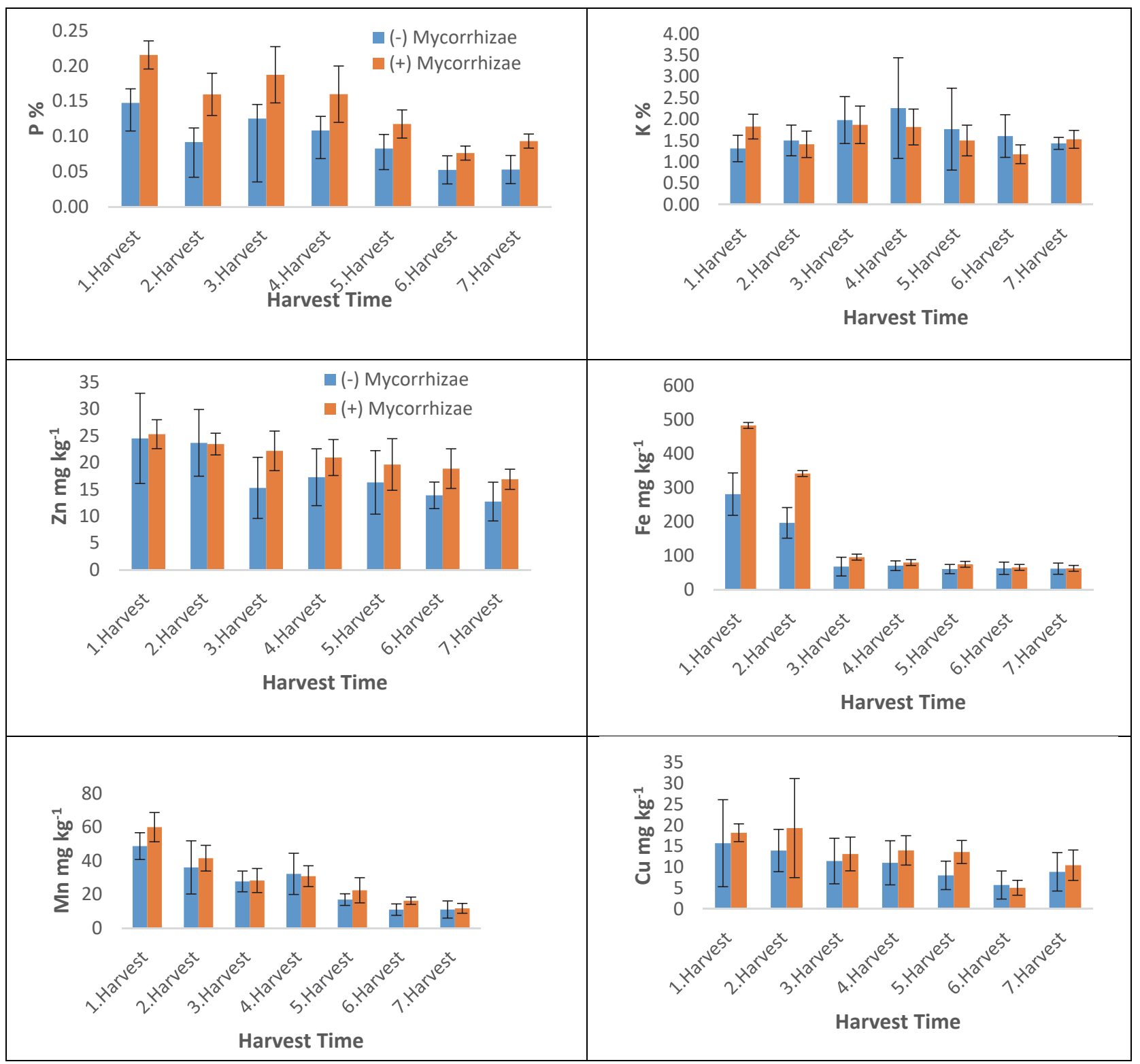

FIGURE 1. Effect of mycorrhizal inoculation on citrus plant nutrient concentration during several harvesting times.

seedlings (Figure 1). The shoot phosphorus concentration in mycorrhiza-inoculated plants was higher than in non-inoculated seedlings. It was determined that a reduction in $\mathrm{P}$ content in the following harvest must be related to plant $\mathrm{P}$ demand and a dilution factor. In general, although mycorrhiza application significantly increases the P concentration, the concentration remains below the critical level $(0.15 \% \mathrm{P})$ (Jones, 1998). In addition, in our previous work, we found that citrus plant $\mathrm{P}$ concentration is usually less than the required levels. In order to elucidate this issue, the critical level of citrus P should be investigated.

In both mycorrhiza and non-mycorrhizal plant tissue, the $\mathrm{K}$ concentration increased up to harvest 4 , then remained stable and subsequently decreased (Figure 1). There is no clear indication that mycorrhiza-inoculated seedlings have a higher K concentration than non-inoculated seedlings. Antunes and Cardoso (1991), Levy and Krikun (1980), and Menge et al. (1982) reported that AM-inoculated citrus plants grow better than non-inoculated ones; in addition, inoculated citrus plants exhibit a higher $\mathrm{P}$ and $\mathrm{K}$ content.

The $\mathrm{Zn}$ concentration was measured in non-inoculated seedlings and at the $1^{\text {st }}$ harvest was $24.52 \mathrm{mg} \mathrm{kg}^{-1}$ and then decreased (Figure 1), with the Zn concentration of 12.73 $\mathrm{mg} \mathrm{kg}{ }^{-1}$ at the $7^{\text {th }}$ harvest. The $\mathrm{Zn}$ concentration in mycorrhiza-inoculated seedlings decreased with harvest time. At the $1^{\text {st }}$ harvest the $\mathrm{Zn}$ was $25.31 \mathrm{mg} \mathrm{kg}^{-1}$ and at the $7^{\text {th }}$ harvest, the tissue $\mathrm{Zn}$ concentration was $16.90 \mathrm{mg} \mathrm{kg}^{-1}$. Mycorrhiza-inoculated seedlings usually have a higher Zn concentration (Ortas et al., 2016) and were found to have a higher Zn concentration than non-inoculated seedlings. For both inoculated and non-inoculated seedlings, the Zn concentration decreased and at harvests 5, 6 and 7, the concentration was less than the critical level (Jones, 1998) (20 mg Zn kg-1). After each harvest, all plant nutrients were analyzed separately and the results have shown that nutrient concentration usually decreased with increasing harvesting time and it seems that there was a time effect on nutrient concentration.

In the $1^{\text {st }}$ and $2^{\text {nd }}$ harvests, the citrus seedlings had higher Fe concentrations than at other harvests, as time increased the leaf tissue Fe concentration decreased (Figure 1). The effect of mycorrhiza and harvest time significantly increased leaf Fe concentration. Usually, Fe values of plants inoculat- 


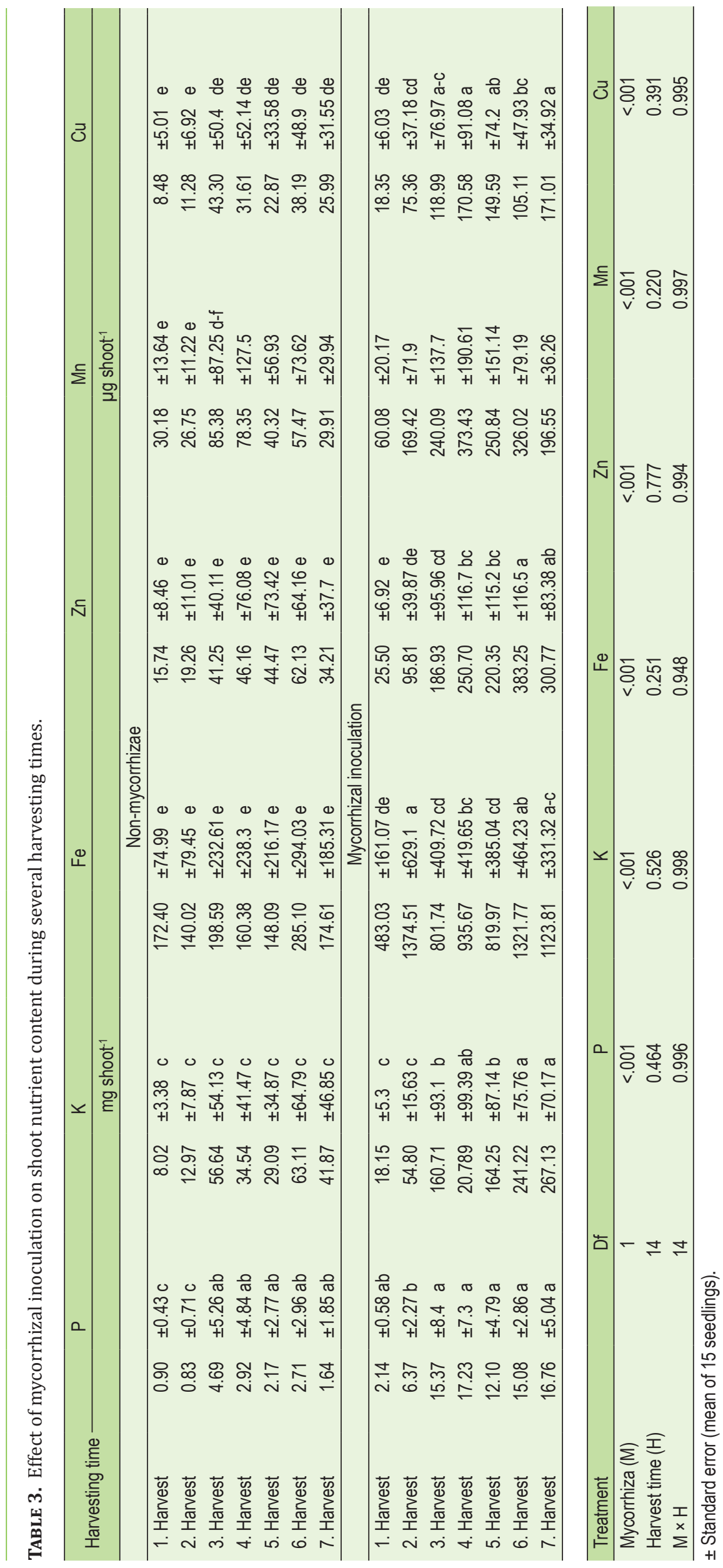


TABlE 4. Mycorrhizal responsiveness for each harvest time. Each harvest analyzed for previous harvest dry weight to determine the mycorrhizal dependency.

\begin{tabular}{lccccccc}
\hline & 1. Harvest & 2. Harvest & 3. Harvest & 4. Harvest & 5. Harvest & 6. Harvest & 7. Harvest \\
\hline 1. Harvest & 54 & & & & & & \\
2. Harvest & 85 & 74 & & & & & \\
3. Harvest & 95 & 91 & 66 & & & & \\
4. Harvest & 96 & 93 & 75 & 75 & & \\
5. Harvest & 96 & 93 & 75 & 77 & 86 & & \\
6. Harvest & 97 & 95 & 82 & 82 & 90 & 86 & 93 \\
7. Harvest & 97 & 95 & 83 & 83 & 90 & 87 & 93 \\
\hline
\end{tabular}

ed with mycorrhizal are higher than non-inoculated plants. The lower Fe concentration at harvests 3 to 7 may have been caused by an increased biomass dilution factor due to plant growth.

The Mn concentration decreased as time increased (Figure 1). At every harvest interval, mycorrhiza-inoculated plants had a higher Mn concentration than non-inoculated plants. The decrease observed in Mn concentration is due to typical dilution effects.

Our findings show that mycorrhiza-inoculated citrus seedlings have a higher $\mathrm{Cu}$ concentration than non-inoculated ones (Figure 1). With time, the seedling $\mathrm{Cu}$ concentration decreased as did $\mathrm{P}, \mathrm{Zn}, \mathrm{Fe}$ and $\mathrm{Mn}$, and in general, the $\mathrm{Cu}$ concentration decreased in the later harvests. Nielsen and Jensen (1983) reported that reduced concentrations of micronutrients in mycorrhiza-inoculated plants can sometimes be attributed to a dilution effect linked to an increase in plant dry matter (DM) yield.

Mycorrhiza-inoculated seedlings have a higher nutrient concentration than non-inoculated ones. Zubek et al. (2015) and Wu et al. (2017) indicated that under controlled conditions, mycorrhiza-inoculated plants have high concentrations of $\mathrm{P}, \mathrm{Zn}, \mathrm{Ca}, \mathrm{Cu}, \mathrm{Mn}, \mathrm{Fe}$ and $\mathrm{Mg}$. At the beginning of growth, seedlings absorbed nutrients more rapidly than later on, due to dilution effects.

With time, the nutrient concentration in the leaf tissue increased and then decreased, which may have been caused by a seasonal temperature change as temperature has a significant effect on nutrient uptake via microbial activity and root development. Paramasivam et al. (2000) also reported that the plant nutrient concentration altered with the changing seasons. Our present and past results show that a turf, andesitic tuff and compost-based GM is suitable for producing good quality mycorrhiza-inoculated seedlings (Ortas and Ustuner, 2014).

\section{Total nutrient uptake}

Plant total nutrient uptake was also calculated in order to determine the dilution effect of plant growth in relation to nutrient concentration. Data are presented in Table 3 and show that in non-inoculated plants, the $\mathrm{P}, \mathrm{K}, \mathrm{Fe}, \mathrm{Zn}, \mathrm{Mn}$ and $\mathrm{Cu}$ nutrient uptake, in general, increased with time up to harvest 6 and/or harvest 7. This means that up to a certain period, plants accumulate nutrients and after that time nutrient uptake declines. Seedling P and K concentration values are in good agreement with the data of Paramasivam et al. (2000). In mycorrhiza-inoculated plants, nutrient uptake continues over time which means that the growth of mycorrhizainoculated plants continues compared with non-mycorrhizal seedlings, or mycorrhiza-inoculated plants live longer (or require nutrients for a longer period) than non-mycorrhizal ones. Whether mycorrhiza inoculation increases the plant life expectation requires further investigation. It is also possible that, at the beginning of plant growth, the nutrient concentration is high in soil and, with time, rhizosphere nutrient depletion occurs which limits nutrient acquisition.

\section{Mycorrhizal responsiveness}

Mycorrhizal responsiveness (MR) was calculated after each harvest, and as can be seen in the matrix table, MR increased with time. At the first harvest, the MR was $54 \%$, at the second harvest the MR was $85 \%$ and at the last harvest the MR was $97 \%$ (Table 4). This means that mycorrhiza inoculation at the first harvest was not sufficient and with time, the effectiveness of mycorrhizae increased. These results are supported by our previous work (Ortas and Ustuner, 2014); in addition, López-Bucio et al. (2003) reported that 180 days of mycorrhizal inoculation the MD of sour orange increased.

\section{Conclusion}

The results show that mycorrhiza inoculation significantly increased seedling shoot and root growth and other growth parameters. As the GM was sterilized, non-inoculated seedlings had very little root colonization, however the root colonization of mycorrhiza-inoculated seedlings started at the $1^{\text {st }}$ harvest, with higher root colonization occurring between the $3^{\text {rd }}$ and $6^{\text {th }}$ harvest.

When the P content of plants was examined it was found that mycorrhiza-inoculated seedlings have a higher $\mathrm{P} \%$ than non-inoculated ones. In both inoculated and non-inoculated seedlings, the $\mathrm{P}$ concentration is high at the beginning; however when the plant biomass increases, the P concentration decreases as a result of dilution effects. The major finding was that the nutrient concentration of the plant leaf, i.e., $\mathrm{P}$, $\mathrm{Zn}, \mathrm{Fe}, \mathrm{Cu}$ and $\mathrm{Mn}$ decreased with time due to dilution effects. The results show that mycorrhiza-inoculated plants have a higher nutrient uptake than non-inoculated ones, and mycorrhiza-inoculated plants take up nutrients for a longer period than non-inoculated ones. Sour orange seedlings are highly dependent upon mycorrhiza and after the $2^{\text {nd }}$ harvest, the MR was over $85 \%$; this data also applies to root colonization. In addition, results show that root colonization of citrus plants occurs 4-5 months after seed germination, which is different to annual crops. The results show a very good correlation between root colonization and mycorrhizae responsiveness.

\section{Acknowledgments}

Thanks to TUBITAK COST 870 (104 0 033) Project for financial support. 


\section{References}

Antunes, V., and Cardoso, E. (1991). Growth and nutrient status of citrus plants as influenced by mycorrhiza and phosphorus application. Plant and Soil 131, 11-19. https://doi.org/10.1007/ BF00010415.

Chen, Y.Y., Hu, C.Y., and Xiao, J.X. (2014). Effects of arbuscular mycorrhizal inoculation on the growth, zinc distribution and photosynthesis of two citrus cultivars grown in low-zinc soil. TreesStructure and Function 28, 1427-1436. https://doi.org/10.1007/ s00468-014-1046-6.

Cho, E.J., Lee, D.J., Wee, C.D., Kim, H.L., Cheong, Y.H., Cho, J.S., and Sohn, B.K. (2009). Effects of AMF inoculation on growth of Panax ginseng CA Meyer seedlings and on soil structures in mycorrhizosphere. Sci. Hortic. 122, 633-637. https://doi.org/10.1016/j. scienta.2009.06.025.

Giovanetti, M., and Mosse, B. (1980). An evaluation of techniques for measuring vesicular-arbuscular mycorrhiza in roots. New Phytol. 84, 489-500. https://doi.org/10.1111/j.1469-8137.1980.tb04556.x.

Jones, J.B. (1998). Plant Nutrition Manual (New York: CRC Publishers).

Koske, R.E., and Gemma, J.N. (1989). A modified procedure for staining roots to detect VA-mycorrhizas. Mycol. Res. 92, 486-488. https://doi.org/10.1016/S0953-7562(89)80195-9.

Kothari, S.K., Marschner, H., and Romheld, V. (1991). Contribution of the VA mycorrhizal hyphae in acquisition of phosphorus and zinc by maize grown in a calcareous soil. Plant and Soil 131, 177-185. https://doi.org/10.1007/BF00009447.

Levy, Y., and Krikun, J. (1980). Effect of vesicular-arbuscular mycorrhiza on citrus-jambhiri water relations. New Phytol. 85, 2531. https://doi.org/10.1111/j.1469-8137.1980.tb04444.x.

Levy, Y., Syvertsen, J.P., and Nemec, S. (1983). Effect of drought stress and vesicular arbuscular mycorrhiza on citrus transpiration and hydraulic conductivity of roots. New Phytol. 93, 61-66. https://doi. org/10.1111/j.1469-8137.1983.tb02692.x.

Li, X.L., George, E., and Marschner, H. (1991). Extension of the phosphorus depletion zone in VA-mycorrhizal white clover in a calcareous soil. Plant and Soil 136, 41-48. https://doi.org/10.1007/ BF02465218.

López-Bucio, J., Cruz-Ramírez, A., and Herrera-Estrella, L. (2003). The role of nutrient availability in regulating root architecture. Current Opin. in Plant Biol. 6, 280-287. https://doi.org/10.1016/ S1369-5266(03)00035-9.

Menge, J.A., Jarrell, W.M., Labanauskas, C.K., Ojala, J.C., Huszar, C., Johnson, E.L.V., and Sibert, D. (1982). Predicting mycorrhizal dependency of troyer citrange on Glomus fasciculatus in California citrus soils and nursery mixes. Soil Sci. Soc. of Am. J. 46, 762-768. https://doi.org/10.2136/sssaj1982.03615995004600040019x.

Murphy, J., and Riley, J.P. (1962). A modified single solution method for determination of phosphate in natural waters. Anal. Chim. Acta 27, 31-36. https://doi.org/10.1016/S0003-2670(00)88444-5.

Nielsen, J.D., and Jensen, A. (1983). Influence of vesicular-arbuscular mycorrhiza fungi on growth and uptake of various nutrients as well as uptake ratio of fertilizer-P for lucerne (Medicago sativa). Plant and Soil 70, 165-172. https://doi.org/10.1007/BF02374777.

Nunes, M.D., Soares, A.C.F., Soares, W.D., and Ledo, C.A.D. (2006). Natural mycorrhizal colonization of citrus rootstocks under field conditions. Pesq. Agropec. Bras. 41, 525-528. https://doi. org/10.1590/S0100-204X2006000300021.

Ortas, İ. (2012a). Mycorrhiza in citrus: growth and nutrition. In Advances in Citrus Nutrition, A.K. Srivastava, ed. (The Netherlands: Springer-Verlag). https://doi.org/10.1007/978-94-007-4171-3_23.
Ortas, İ. (2012b). Mycorrhiza in citrus: growth and nutrition. In Advances in Citrus Nutrition, A.K. Srivastava, ed. (The Netherlands: Springer-Verlag), p. 333-351.

Ortas, İ., and Ustuner, O. (2014). Determination of different growth media and various mycorrhizae species on citrus growth and nutrient uptake. Sci. Hortic. 166, 84-90. https://doi.org/10.1016/j. scienta.2013.12.014.

Ortas, İ., Ortakci, D., and Kaya, Z. (2002). Various mycorrhizal fungi propagated on different hosts have different effect on citrus growth and nutrient uptake. Commun. in Soil Sci. and Plant Anal. 33, 259272. https://doi.org/10.1081/CSS-120002392.

Ortas, İ., Akpinar, C., and Demirbas, A. (2016). Sour Orange (Citrus aurantium L.) growth is strongly mycorrhizal dependent in terms of phosphorus (P) nutrition rather than zinc (Zn). Commun. in Soil Sci. and Plant Anal. 47, 2514-2527. https://doi.org/10.1080/00103624. 2016.1254792.

Page, L.A., Miller, R.R., and Keeney, D.R. (1982). Methods of Soil Analysis, Part 2. Chemical and Microbiological Properties (Madison, USA: ASA-SSSA).

Paramasivam, S., Alva, A.K., Hostler, K.H., Easterwood, G.W., and Southwell, J.S. (2000). Fruit nutrient accumulation of four orange varieties during fruit development. J. Plant Nutr. 23, 313-327. https://doi.org/10.1080/01904160009382018.

Schüßler, A., and Walker, C., eds. (2010). The Glomeromycota: a species list with new families, (Edinburgh: The Royal Botanic Garden; Kew: The Royal Botanic Garden; Munich: Botanische Staatssammlung; and Corvallis, OR: Oregon State University). http:// www.amf-phylogeny.com.

Sharma, S.D., Kumar, P., Singh, S.K., and Patel, V.B. (2009). Indigenous AM fungi and Azotobacter isolates, and their screening from citrus seedlings at different levels of inorganic fertilizers application. Indian J. Hortic. 66, 183-189.

Srivastava, A.K., Singh, S., and Marathe, R.A. (2002). Organic citrus: soil fertility and plant nutrition. J. Sustain. Agric. 19, 5-29. https:// doi.org/10.1300/J064v19n03_03.

Wang, M., and Xia, R. (2009). Effects of arbuscular mycorrhizal fungi on growth and iron uptake of Poncirus trifoliata under different $\mathrm{pH}$. Weishengwu Xuebao 49, 1374-1379.

Wu, Q.S., Srivastava, A.K., Zou, Y.N., and Malhotra, S.K. (2017). Mycorrhizas in citrus: Beyond soil fertility and plant nutrition. Indian J. Agric. Sci. 87, 427-443.

Wu, Q.S., and Xia, R. (2005). Effects of AM fungi on drought tolerance of citrus grafting seedling trifoliate orange/cara cara. Yingyong Shengtai Xuebao 16, 865-869.

Wu, Q.S., and Zou, Y.N. (2009). Mycorrhizal influence on nutrient uptake of citrus exposed to drought stress. Philippine Agric. Sci. 92, 33-38.

Wu, Q.S., Zou, Y.N., and He, X.H. (2010). Exogenous putrescine, not spermine or spermidine, enhances root mycorrhizal development and plant growth of trifoliate orange (Poncirus trifoliata) seedlings. Int. J. Agric. and Biol. 12, 576-580.

Youpensuk, S., Lordkaew, S., and Rerkasem, B. (2008). Arbuscular mycorrhizal fungi associated with tangerine (Citrus reticulata) in Chiang Mai province, northern Thailand, and their effects on the host plant. ScienceAsia 34, 259-264. https://doi.org/10.2306/ scienceasia1513-1874.2008.34.259.

Zubek, S., Rola, K., Szewczyk, A., Majewska, M.L., and Turnau, K. (2015). Enhanced concentrations of elements and secondary metabolites in Viola tricolor L. induced by arbuscular mycorrhizal fungi. Plant and Soil 390, 129-142. https://doi.org/10.1007/ s11104-015-2388-6. 
Received: Oct. 10, 2017

Accepted: Feb. 20, 2018

Addresses of authors:

İbrahim Ortas ${ }^{1, *}$, Ahmet Demirbas ${ }^{2}$ and Cagdas Akpinar ${ }^{3}$

${ }^{1}$ University of Çukurova, Department of Soil Science and Plant Nutrition, Adana, Turkey

${ }^{2}$ Department of Crop and Animal Production, Sivas

Vocational School, University of Cumhuriyet, Sivas,

Turkey

${ }^{3}$ Department of Organic Farming Business Management, Kadirli School of Applied Sciences, University of Osmaniye Korkut Ata, Osmaniye, Turkey

* Corresponding author; E-mail: iortas@cu.edu.tr Tel. and fax: +903223386643 